\title{
La educación del siglo XXI: un proceso de formación integral de la persona humana
}

\author{
$21^{\text {st }}$ century education: a process of integral formation of human person
}

\author{
Wilfredo Montenegro Carrasco* \\ Facultad de Ciencias de la Comunicación, Turismo y Psicología, \\ Universidad de San Martín de Porres, Perú
}

\section{Resumen}

La educación del hombre es un tema que no deja de ser cuestionado. A pesar de los esfuerzos y de las diversas innovaciones en la materia, la crisis educativa de la «sociedad líquida» es cada vez más profunda y al mismo tiempo más relativa (Bauman, 2004). El hombre y sus actitudes, hoy fuertemente controvertidas por sus manifestaciones de violencia, irracionalidad, corrupción y rechazo de los valores, revelan la cruda realidad educativa. Frente a la situación descrita, la presente investigación se propone analizar las raíces de esta problemática y a la vez proponer reflexiones y alternativas innovadoras que ayuden a superar dicha crisis.

Los resultados encontrados son reveladores y esperanzadores. Varios de los planteamientos de este trabajo ya están contemplados en la legislación y en la teoría educativa desde hace varias décadas; sin embargo, han quedado en el olvido por efectos del individualismo, la anomia, el escepticismo y el nihilismo propios de la sociedad posmoderna. El aporte factible y necesario es la educación sistémica de la persona que, superando los diversos reduccionismos, se centre en el «desarrollo humano integral» (Benedicto XVI, 2009); dejando en claro, asimismo, los roles de la familia, del Estado, de la escuela, de los medios de comunicación social, de la sociedad y del mismo educando frente al desafío de la educación actual.

Este es un artículo Open Access bajo la licencia Creative Commons Atribución-NoComercial-Compartirlgual 4.0

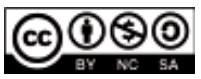


Palabras clave: formación integral, currículo integral, acreditación de la calidad educativa, innovación educativa, rol de los agentes educativos.

\begin{abstract}
The education of man is an issue that continues to be questioned. Despite the efforts and various innovations in the field, the educational crisis of the «liquid society» is increasingly deep and at the same time more relative (Bauman, 2004). The man and his attitudes, today strongly controversial due to their manifestations of violence, irrationality, corruption and rejection of values, reveal the harsh educational reality. Faced with the situation described, this research aims to analyze the roots of this problem and at the same time propose reflections and innovative alternatives that help to overcome said crisis.
\end{abstract}

The results found are revealing and encouraging. Several of the approaches of this work have already been contemplated in the legislation and in educational theory for several decades; however, they have been forgotten by the effects of individualism, anomie, skepticism and nihilism typical of postmodern society. The feasible and necessary contribution is the systemic education of the person that, overcoming the various reductionisms, focuses on «integral human development» (Benedict XVI, 2009); making clear, also, the roles of the family, the State, the school, the media, society and the same educating against the challenge of current education.

Keywords: comprehensive training, comprehensive curriculum, accreditation of educational quality, educational innovation, role of educational agents.

\title{
Introducción
}

La crisis moral que caracteriza a los tiempos actuales exige una revolución educativa, la que intentamos presentar a partir del análisis de las debilidades y fortalezas del sistema vigente. Los desafíos del licenciamiento y acreditación de la calidad de la educación son estrategias que buscan mejorar los resultados de la observación y evaluación de dicha calidad 
realizadas por expertos nacionales e internacionales, quienes siguen ubicando a la educación peruana en los niveles más bajos (Alarcón et al., 2018). La superación de tales resultados necesita ser abordada como una prioridad para alcanzar los estándares esperados. Los estudiantes terminan la secundaria no solo con diversas deficiencias académicas relacionadas con bajas calificaciones, sino con conductas muy polémicas por su alta dosis de agresividad, consumo de drogas, uso ilegal de armas y actitudes discriminatorias (Leuridan, 2021).

Las sociedades que no han desarrollado altos estándares educativos son estereotipadas como pobres, tercermundistas y subdesarrolladas. Las propuestas del conductismo, del cognitivismo y del constructivismo -este último inspirado en el desarrollo de competencias y capacidades determinadas por el sistema mercantil globalizado (el neoliberalismo), sin considerar la dimensión humana de integralidad- han fracasado. Dicho sistema ha producido al hombre mediocre, al hombre de anomia, al hedonista, vulgar y libertino, al hombre poco productivo y al hombre sin valores y sin disciplina (Leuridan, 2021). Esta situación pone en evidencia la necesidad de una nueva visión educativa.

En realidad, la educación del hombre es un tema que nunca ha terminado de definirse como tal. A través de la historia se han ensayado diversas definiciones o ideas al respecto, casi todas parciales. Esa parcialidad o reduccionismo no ha sido capaz de responder a las características de la compleja naturaleza humana (Peñaloza, 2005). Ese es el caso de la educación actual que ha formado al hombre alienado, al hombre de la «sociedad líquida», al hombre dependiente, incapaz de responsabilizarse de su propio destino (Bauman, 2004).

Las discusiones sobre si la educación es un derecho o un privilegio de algunos son otro tema de nunca acabar; ni la crítica ni las necesidades humanas insatisfechas (Maslow, como se citó en Turienzo, 2016) han podido romper con este dilema. Se hace necesario escuchar también el grito de los indignados, de los excluidos del sistema educativo (Dussel, 2011).

Hablar de los fines educativos genera igualmente gran polémica. La sociedad globalizada reduce estos fines a los objetivos del mercado. La 
educación como inserción social, la educación para el trabajo y la educación técnica crean al hombre productivo, pero no al hombre libre y realizado.

Como muchos otros problemas, la crisis educativa es también objeto de la falta de responsabilidad. Todos se lavan las manos. La familia y el Estado (ministerios de Educación) son los más señalados como culpables, aunque en realidad solo son responsables parcialmente. También participan de esta responsabilidad los medios de comunicación y otras instituciones que tienen una gran repercusión social.

La crisis educativa obedece además a políticas de inversión precarias. En los países latinoamericanos la educación no es una prioridad dentro del gasto social. El caso del Perú es paradigmático, pero no único: se invierte más dinero en resocializar delincuentes que en educar a niños y jóvenes. La inversión privada se centra menos en intereses humanos y más en intereses empresariales.

El diseño curricular también ha seguido la suerte de las tendencias impuestas por las corrientes modernas, plagadas de materialismo, individualismo y economicismo. Los cursos están organizados sobre el eje de la búsqueda de resultados materiales: más producción, más riqueza... y menos humanización. Se trata de una robotización del hombre. El Hombre Máquina de Descartes y el hombre económico caracterizado por la pobreza se han hecho realidad.

Hablar de calidad educativa se ha convertido en un problema para las instituciones del Estado y para los inversores. Muchas de ellas -sobre todo universidades- han tenido que cerrar por no cumplir con los estándares nacionales e internacionales de calidad educativa. La educación pública, con signos visibles como en otros sectores del Estado, está plagada de mediocridad, de corrupción en la gestión y de un notorio abandono tanto en la formación docente como en la infraestructura. Por su parte, la educación privada -sin desmerecer la inversión y los avances de muchos de sus establecimientos- sigue siendo solo una estrategia de mercado, centrada en el negocio y en el lucro, al margen de los fines de la educación humana y de la calidad educativa que el Estado propone. Cuando la educación se convierte en una empresa, el perfil del educando desaparece o simplemente se reduce a los objetivos del mercado. 
La innovación tecnológica en los países de América Latina, incluyendo al Perú, ha generalizado a los «nativos digitales» (Prensky, 2001, como se citó en Cabra y Marciales, 2009). En realidad, el proceso educativo actual solo logra producir consumidores de tecnología. Según recientes informes del portal de transparencia del Ministerio de Educación (MINEDU), miles de estudiantes han desertado por no tener energía eléctrica en sus casas y menos aún una computadora o un celular con Internet. La tecnologización de la educación es un privilegio de quienes la pueden consumir y el Estado hace poco o nada por ayudar a los que no tienen acceso.

En lo que concierne a la innovación educativa integral, hay una resistencia sistemática al fomento de los valores. El consumismo de la tecnología ha creado una dependencia pragmática en los jóvenes. Incluso los que tienen acceso a la tecnología la usan más para entretenerse, para jugar o para perder el tiempo. La exclusión de los cursos humanísticos del currículo educativo y la crisis social manifestada en la violencia y el caos son evidencias de la grave crisis en innovación educativa integral.

Frente a esta complejísima problemática, el presente estudio se propone realizar un exhaustivo análisis de lo que le sucede al sistema educativo peruano, pero sobre todo plantear propuestas innovadoras para la superación de la crisis y que se ponen sobre la mesa para la crítica, el diálogo y la controversia.

Se asume como método el análisis propio de los estudios filosóficos o cualitativos. En todos los temas se fundamentará el problema a partir de las críticas de expertos que aquí citaremos, se dialogará con ellos y, finalmente, se presentarán las alternativas de solución. La intención es, en primer lugar, generar una nueva visión educativa, vinculada a los imperativos de la naturaleza humana. Sin embargo, el optimismo de esta investigación se proyecta a los cambios efectivos que la educación humana del siglo XXI necesita.

Finalmente, dejamos constancia de que este estudio es solo uno más de los que ya existen en la cadena de eslabones de la investigación educativa. Así como aporta importantes innovaciones en torno a estos temas, también presenta limitaciones relacionadas con las deficiencias propias del enfoque de cada autor y de la crítica, que siempre tendrá algo que observar. 


\section{Definición de educación}

La educación se define como la formación integral de la persona humana: el desarrollo de sus capacidades intelectuales, morales y afectivas, de su propia cultura y de las normas de convivencia de la sociedad en la que se desenvuelve. Incluye también la transmisión de valores de la sociedad a la persona, con el fin de que adquiera una determinada formación. La investigación, el debate, la narración de cuentos, la discusión, la enseñanza, el ejemplo y la formación en general son estratégicos para el desarrollo de la educación integral (Paulo VI, 1965a, Gravissimum Educationis [GE], 5).

La educación se define también como el máximo bien común y el único camino para el desarrollo de los pueblos. La verdadera educación trasciende el aprendizaje de conocimientos, habilidades y destrezas; apunta a la formación de las capacidades cognitivas, culturales, afectivas, axiológicas, científicas, tecnológicas, ético-morales y espirituales de la persona (GE, 5).

Desde la filosofía, la educación se define como un proceso racional y libre que necesita el conocimiento y práctica de la norma, la comprensión y vivencia del afecto, y la transmisión de valores mediante el ejemplo de los adultos. El discernimiento racional sobre el sentido de la norma ayuda al hombre a ser disciplinado; sobre el afecto, le da sentido a la práctica del respeto, la amistad y el amor en las diversas relaciones humanas; y sobre el ejemplo, permite la imitación de lo bueno y el repudio de lo malo. «La educación es lograda cuando se ha podido transmitir a los niños el amor (elemento cristiano), la ley (elemento judío) y las obras literarias (elemento griego)» (Leuridan, 2021, p. 291).

La educación es norma. Implica el conocimiento y práctica de las diversas regulaciones de convivencia humana que deben desarrollarse en todos los contextos y sin las cuales la sociedad sería caótica. La norma orienta el orden y da origen a la disciplina, permitiendo relaciones de alteridad armoniosas y responsables. Las leyes, las normas éticas y morales de una sociedad, deben ser la plataforma de formación del hombre disciplinado. La ley no se discute ni se negocia, de lo contrario se cae en el relativismo y en la anomia. La ley debe ser valorada porque promueve la convivencia pacífica con los demás, la práctica del respeto y el cumplimiento de las responsabilidades (Leuridan, 2021). 
Las acciones de respeto profundo, la escucha atenta y el trato cordial y humano hacen que la educación sea también afecto, el cual debe promoverse -igual que las normas- en todos los contextos. Los resultados de la investigación psicológica afirman que todos los seres humanos, sobre todo en la etapa de la niñez, necesitan recibir amor (valoración y aprecio), de manera que alcanzada la edad adulta tengan una gran estima de sí mismos y de los demás; y, al mismo tiempo, estén preparados para enfrentarse a los desafíos que la vida les presente (Leuridan, 2021).

La educación es ejemplo (Savater, 1997) piensa que el ser humano, al menos en las etapas iniciales de su vida, es imitación. Por ello, el buen o mal ejemplo tienen una gran influencia en la conducta de la juventud. El dicho popular «de tal palo tal astilla» manifiesta el nivel de importancia que tiene el ejemplo en la educación, pues de él depende la formación de sociedades con desarrollo humano integral.

Para Peñaloza (2005) la educación es un proceso complejo e integrador con tres componentes: hominización, socialización y aculturación. La primera se refiere al hecho de que el hombre es un proyecto inacabado que precisa del desarrollo de diversos elementos para lograr su realización integral. Su socialización o interacción con los demás revela su significado de alteridad y humanidad, y le da sentido al bien común, el principio social más importante. Finalmente, el hombre está llamado a seguir creando su mundo y la cultura es el ambiente que él ha erigido para su vida. Las sociedades que no prioricen la educación están condenadas a la involución, al individualismo, al rechazo de la moral y la cultura, y -por ende- a sufrir las consecuencias.

\section{La educación como derecho universal}

Frente a las concepciones o prejuicios que consideran a la educación un privilegio exclusivo de quienes pueden pagar sus estudios, desde hace varias décadas se viene luchando por el derecho a una educación universal e inclusiva.

Todos los hombres, de cualquier raza, condición y edad, en cuanto participantes de la dignidad de la persona, tienen el 
derecho inalienable de una educación, que responda al propio fin, al propio carácter; al diferente sexo y que sea conforme a la cultura y a las tradiciones patrias, y, al mismo tiempo, esté abierta a las relaciones fraternas con otros pueblos, a fin de fomentar en la tierra, la verdadera unidad y la paz. La verdadera educación se centra en la formación de la persona humana, en orden a su fin último (su felicidad) y al bien de la sociedad, de la que el hombre es miembro, y de cuyas responsabilidades deberá tomar parte, una vez llegado a la madurez (GE, 1).

La educación debe ser como el agua y el sol, accesible para todos. Las familias que no estén en capacidad de poder brindar una educación integral a sus hijos deben recibir el apoyo subsidiario del Estado o de las instituciones educativas. El Art. 26 de la Declaración Universal de los Derechos Humanos (1948) pone a la persona humana como centro, y condena todo tipo de discriminación, ubicando a la educación como uno de sus derechos más importantes. En las sociedades donde esta no se respeta ni se promueve, donde los pobres y las mujeres son excluidos de ella, hay una clara violación de los derechos humanos (Comisión de Derechos de la ONU, 1948).

\section{Los propósitos de la educación integral}

El único fin de la educación es la realización plena del hombre; lo social, lo económico y lo cultural son medios necesarios, pero solo eso. Peñaloza (2005) sostiene que «todo proceso educativo posee un carácter teleológico. La educación es un proceso de transformación humana en función de unas finalidades y propósitos especialmente en el plano axiológico» (p. 41), donde el valor más importante es la persona, lo que en una visión más amplia trasciende incluso a la familia. El currículo es determinante en la afectación de los fines educativos, su influencia positiva o negativa está en función de su cumplimiento o incumplimiento. El éxito de la educación depende prioritariamente de la elección de sus objetivos en la planificación curricular. En muchos países del mundo donde hay un gran desarrollo económico, tecnológico y científico, los problemas de pobreza, violencia e impunidad de los crímenes contra los derechos humanos son un dolor de cabeza. Por 
lo tanto, el desarrollo humano integral es más que desarrollo económico o científico.

Merece una profunda reflexión la propuesta de Jacques Delors (1994), quien sostiene que el siglo XXI ofrece recursos sin precedentes que facilitan la circulación y el almacenamiento de información. Las tecnologías de la comunicación social son un desafío para la educación actual ya que, ciertamente, favorecen la transmisión de saberes teóricos y técnicos, acordes con lo que pide la sociedad del conocimiento. Pero la educación debe ayudar al estudiante a discernir y seleccionar contenidos significativos y útiles al desarrollo humano integral. Las políticas educativas deben asumir el reto de diseñar un plan adecuado a este desarrollo.

Para estar a la altura de las exigencias del hombre actual, la educación necesita estructurar cuatro aprendizajes fundamentales: «aprender a conocer» lo desconocido y comprenderlo para hacer de ello una herramienta útil en su realización integral; «aprender a hacer», para poder transformar e influir en su entorno social; «aprender a vivir juntos», cooperando en el desarrollo de mejores niveles de convivencia humana, en pro de la paz; $y$, por último, «aprender a ser», que apunta al desarrollo integral de la persona humana. Las cuatro vías del saber convergen en una sola: la formación integral del hombre como único fin educativo (Delors, 1994).

\section{Los entes responsables de la educación del hombre}

La sociedad se enfrenta a cuestiones difíciles, como el reto de capacitar a los padres para que dediquen más tiempo a sus hijos, frente a la necesidad de tener dos trabajos a tiempo completo para cubrir las necesidades básicas de subsistencia. No obstante, tienen el deber ineludible de contribuir a la educación de su prole, con el ejemplo, la práctica de valores y la disciplina (Montenegro, 2020).

La vida familiar y la vida social tienen una influencia mutua. El Estado influye en la familia con sus políticas públicas de desarrollo; por su parte, la familia y la escuela influyen en el Estado y en la sociedad con la formación de ciudadanos consolidados. La humillación y la crueldad con los demás son signos de una educación sin valores. La familia constituye el 
fundamento de la sociedad, motivo por el que debe ser considerada y reconocida, institucionalizada por el matrimonio y consecuentemente protegida, sobre todo en lo que se refiere a su influencia en la moral pública y en el derecho a su propia prosperidad (Paulo VI, 1965b; Leuridan, 2021).

La educación es un asunto de los padres en relación con sus hijos y es la tarea de los docentes empleando el dinamismo de la enseñanza-aprendizaje. La familia y el maestro se dirigen al niño en todas las dimensiones de su personalidad. Aunque los docentes no son los padres de los alumnos, su sabiduría y su ejemplo tienen una gran influencia en ellos. Una debilidad del sistema educativo se manifiesta en que la escuela no puede reemplazar a la familia donde esta fracasa, hecho que implica considerar dentro de dicho sistema, y con razones suficientes, una preparación previa para quienes decidan formar una familia y -consecutivamente- establecer estrategias para ayudarlos a consolidar esta preparación en relación con la delicada tarea de la formación de niños y jóvenes.

A continuación, se exponen los diversos roles, que de hecho son complementarios, de todos los agentes educativos. La familia, la escuela, el Estado, las instituciones de toda índole y la sociedad tienen una responsabilidad compartida en la educación de las nuevas generaciones.

\subsection{El rol de la familia en la educación de los hijos}

Desde hace varias décadas se ha anunciado el «eclipse de las familias» (Savater, 1997, p. 27). La disfuncionalidad familiar y la descensión estudiantil, factores determinantes de la crisis educativa, muestran la debilidad de las familias frente al reto de contribuir con la educación integral de sus hijos. Esta situación, unida a la pobreza cultural y socioeconómica de muchas de ellas, hace que la educación deje de ser un derecho y un deber, y se convierta en una simple alternativa, casi siempre olvidada.

Educar es una responsabilidad de la familia, pero es también una responsabilidad social. La educación se inicia en la infancia y se va proyectando en las diversas etapas de la vida en relación con los diversos 
niveles de adquisición del conocimiento. La escuela necesita del aporte de las familias, sobre todo en la etapa previa a la escolaridad. La familia es el punto de partida de la educación afectiva: el amor, el respeto, el buen trato de los padres a los hijos, unidos a los gestos, los preparan para el éxito en la etapa escolar (Montenegro, 2016).

\subsection{El rol de la escuela en la educación del hombre nuevo}

La infancia, la educación inicial y la primaria son momentos adecuados y propicios para el aprendizaje diversificado de conocimientos, capacidades y destrezas. Gracias a la escuela, el hombre puede cultivar sus facultades intelectuales, desarrollar su capacidad del recto juicio, penetrar en el patrimonio de la cultura conquistado por las generaciones pasadas y promover el sentido de los valores. También prepara a las nuevas generaciones para la vida profesional, fomenta el trato amistoso entre los estudiantes, la mutua comprensión, la vida cultural, cívica y espiritual, así como el trabajo y la participación en la promoción del bien común (GE, 5).

Los retos de la escuela señalados en el párrafo anterior precisan de maestros con capacidades y dones especiales, tanto académicos como afectivos. Las habilidades fuertes y las blandas son requisitos del perfil docente; además de tener una disposición permanente para renovarse y adaptarse (GE, 5).

En el currículo educativo vigente se insiste en el desarrollo de competencias direccionadas al progreso de la ciencia, de la tecnología y de la economía, pero el fomento de capacidades de discernimiento y reflexión ha sido extirpado. Nussbaum (como se cita en Leuridan, 2021), manifiesta su preocupación por el hecho de haberse quitado el financiamiento a los cursos reflexivos en varios países del mundo. Filosofía, ética, axiológica, valores y espiritualidad no aparecen en el currículo educativo y si aparecen es solo como relleno. El problema es que las políticas del sistema educativo actual obedecen más a las demandas del mercado. Savater (1997) observa que dicho sistema se aleja de los fines humanos (realización, ciudadanía y felicidad) y se acerca más a los fines empresariales (optimización de la producción). 
Es un error culpar de la crisis educativa solo a los ministerios de Educación y a los docentes, con sus deficientes planes de estudio y prácticas pedagógicas. La raíz del problema está en la sociedad. El enemigo de la educación, de la familia y de la escuela es la cultura de una sociedad sin valores. Vivimos en una sociedad amoral. Se promueve la idea de que el docente es solo un facilitador del aprendizaje, que este se sustenta en el descubrimiento y en la autonomía (constructivismo). Se subestima la transferencia de conocimientos de la tradición y con ello se menoscaba la autoridad y el ejemplo del maestro. «Un niño no va a inventar cinco mil años de ciencia, tecnología y cultura. Nadie a los diez años llegó a ser un gran pintor, filósofo, piloto, futbolista o científico. Ninguno de nosotros inventó un idioma» (Leuridan, 2021).

Creo que es momento de reconocer el rol fundamental del maestro y de la escuela en la formación integral de la persona humana (Montenegro, 2018). Tampoco la motivación precede al trabajo, es el trabajo el que precede a la motivación. La tarea puede ser dura y sufrida, pero uno sigue adelante porque sabe que es necesario y vale la pena. Kant proponía tres pedagogías: la del juego, la de la enseñanza y la del trabajo (Leuridan, 2021).

Finalmente, la educación universitaria, ultimo nivel educativo, merece una especial atención. El Estado debe valorar a la universidad tanto estatal como privada. Definitivamente ambas contribuyen de manera determinante al desarrollo de la sociedad, por lo que se debe promover su creación y fortalecer las que ya existen. Actualmente, la educación universitaria adolece de mediocridad, indiferencia y corrupción; directores y docentes priorizan sus intereses particulares por encima del bien común. El individualismo y los intereses propios podrían destruir los fines educativos.

Según Salazar (2020), asociaciones educativas, colegios, institutos y universidades están exonerados de aproximadamente cien millones de soles anuales en tributos. La responsabilidad social de estas instituciones, que no dejan de ser empresas, debe manifestarse en subsidios o becas a los mejores estudiantes y maestros. 


\subsection{El rol de los medios de comunicación social en la educación del hombre пиеvo}

El rol de la comunicación social es fundamental en el desarrollo de la cultura de un pueblo. Johan Leuridan Huys, formador de varias generaciones de periodistas, publicistas, relacionistas públicos, especialistas en televisión y radio -hasta hace poco decano de la Facultad de Ciencias de la Comunicación, Turismo y Psicología de la Universidad de San Martín de Porres-, sostiene que «sin el periodismo se viviría en un estado salvaje. El periodismo tiene la tarea sagrada e indispensable de informar y hacer reflexionar sobre la problemática y las decisiones que se tomen para el bien o para el mal, en una sociedad» (Leuridan, 2021, p. 31).

Sin embargo, a pesar de ser reconocidos por la ley como indispensables en la consolidación de la cultura de toda sociedad, los mass media promueven una cultura muy peculiar, alejada de los intereses educativos. En nuestro medio, el rating, el escándalo, la diversión sin sentido, etc. constituyen la cultura de los medios de comunicación.

César Hildebrandt (2021), considerado el periodista más representativo de nuestro tiempo, sostiene que la prensa peruana no está interesada en la verdad, sino justamente en lo contrario: en encubrirla y omitirla, en mentirle a la gente. Tal situación constituye el naufragio de la prensa actual, porque si a esta no le interesa la verdad, deja de ser prensa. La prensa y los diversos medios de comunicación simplemente siguen la lógica del mercado. Sus acciones comunicativas son más destacadas e impactantes dependiendo de la recaudación económica. A mayor recaudación mayor difusión, sin importar la verdad de lo que se difunde. La ética y sus principios básicos: la verdad, la confianza, la credibilidad y el diálogo se han relativizado. La televisión contribuye a ahondar la crisis ética, cultural y social de los pueblos, y en las últimas décadas promueve pobreza y violencia social y cultural, pero no educación ni cultura (Oppenheimer, 2006; Sartori, 1997 y 2011, como se citó en Leuridan, 2021).

La televisión e Internet (las redes sociales) se han convertido en creadoras de la realidad. La virtualidad es la justificación adecuada para incurrir en el hiperrealismo y editar los datos de acuerdo a la conveniencia de 
quien mejor financia. La información está plagada de imágenes, supuestamente sustentatorias, que en el fondo son solo un vértigo visual, parecido a lo que sucede en las películas de ficción. La atracción está en mostrar armas, horror, placer, sexo, venganza, con el fin de saturar, abotagar la conciencia, el juicio crítico y destruir el sentido de realidad. La proclamación nietzscheana del «Dios ha muerto», que significó el rechazo de la razón, es también el anuncio de la muerte de la verdad (Feinmann, 2008, como se citó en Leuridan, 2021).

La CBS, una de las cadenas más grandes de televisión mundial, sostiene que es cuestión de libertad, que el espectador debe decidir qué programa ver. La televisión difunde lo que incrementa la teleaudiencia. «Este comentario es escalofriante por su miopía y su cinismo: descarga sobre el público las culpas que, en realidad, tienen los medios de la comunicación» (Sartori, 1997, como se citó en Leuridan, 2021, p. 32).

Los medios de comunicación social (MCS) se caracterizan por difundir publicidad, una de las actividades más lucrativas, donde se puede cobrar por segundo lo que se transmite, permitiendo ganancias tanto para quienes compran la publicidad como para sus difusores. En este contexto, el rol de estos medios como promotores de la cultura y de la formación moral de la sociedad pasa a segundo plano o desaparece. La televisión es el caldo de cultivo donde crece el libertinaje como expresión del poder económico. Es más importante alcanzar el éxito del consumo que la verdad de lo que se consume (Methol Ferré, 2015, como se citó en Leuridan, 2021).

Los MCS deben asumir su compromiso, inherente a sus funciones, de brindar información veraz y objetiva, en pro del desarrollo cultural y social de la persona humana. «Los medios de comunicación social deben colaborar con el Estado en la educación y en la formación moral y cultural de la sociedad» (Constitución Política del Perú [CPP], 1993, Art. 14).

\subsection{El rol del Estado y la sociedad civil en la educación del hombre nuevo}

El camino adecuado para el ejercicio de la función estatal reside en las políticas sociales direccionadas a la formación íntegra de la persona y a la educación como derecho humano. La función del Estado en la mejora de la educación es determinante, de él dependen las políticas educativas 
materializadas en leyes efectivas, el presupuesto adecuado destinado al sector y los procesos de fiscalización y control. La crisis política -evidenciada en la mediocridad, la improvisación y la corrupción de sus dirigentes- debe cambiarse por una nueva cultura en este ámbito, que forje estadistas con vocación de servicio, meritocracia y prestigio ganado (CPP, 1993, Art. 14).

Las políticas educativas y una inversión económica adecuada deben procurar que todos los ciudadanos tengan acceso a una conveniente participación de la cultura, que se difunde gracias al sistema educativo. De este modo, podrán prepararse debidamente para el cumplimiento de sus derechos y deberes ciudadanos. En ese sentido, se debe proteger el derecho de los niños a una educación escolar conveniente y el deber de los maestros de buscar un adiestramiento eficiente que desarrolle sus capacidades. La función subsidiaria, la diversificación de los aprendizajes, la interculturalidad en relación con el progreso, la difusión de la cultura y la convivencia pacífica son tareas que el Estado debe asumir (GE, 6).

Los maestros de estos tiempos han sido abandonados por el Estado y engañados por instituciones caracterizadas por la demagogia. La calidad de la educación depende no solo de las mejoras en infraestructura y tecnología, sino sobre todo del docente: la educación es el docente; por ello, el Estado subsidiario debe centrarse en su especialización.

La sociedad civil organizada es otro agente educativo indispensable. Cuando el Estado no es capaz de reconocer los derechos inherentes a la educación, el pueblo debe manifestarse para reclamar mejores oportunidades educativas, mejores condiciones de infraestructura y tecnología, ventajas subsidiarias y económicas para el desarrollo de un sistema educativo acorde con las exigencias de la educación integral.

\subsection{El rol de la empresa en la educación del hombre nuevo}

Las empresas de todos los rubros son las primeras que se benefician de los profesionales. El recurso humano especializado, formado en universidades, constituye la garantía del éxito empresarial. Quienes contratan personas con baja capacitación tienen que hacer inversiones 
adicionales para compensar esas carencias. Esto significa que también para las empresas es conveniente que contribuyan con la educación de sus futuros trabajadores, teniendo en cuenta que sus éxitos y permanencia están ligados a la sociedad en general y a quienes consumen sus productos en particular; situación que las compromete a colaborar con la educación de las nuevas generaciones (GE, 7), a asumir ese compromiso utilizando los aportes de responsabilidad social.

\subsection{El rol del estudiante en su autoformación}

León Trahtemberg (2016) critica al sistema educativo tradicional por limitarse a transmitir a las nuevas generaciones lo que tiene preparado. Es una imposición al alumno desde fuera: cuadernos, libros, ejercicios, programas y sílabos. El conductismo enraizado en este sistema hace que el educando asuma lo que otros quieren, que no necesariamente es de su interés. Frente a este proceso, que puede terminar en alienación, el autor propone reconocer que cada estudiante es un universo, una totalidad, con deseos propios, ideas, inteligencia, curiosidades, capacidades para explorar y aprender. Los contextos deben adecuarse para que quiera aprender y disfrute al hacerlo. La idea es construir estos contextos a partir de lo que el alumno trae a la clase.

La observación de Trahtemberg puede inducir a una educación cognitivista, en la que el alumno es el protagonista principal de su formación, hecho que, en realidades como la peruana, donde los estudiantes son básicamente hedonistas incrementaría la crisis educativa. El verdadero sentido de la enseñanza-aprendizaje está en la interacción. Sin necesidad de restarle elementos a la educación tradicional, es el estudiante quien desde su propia autonomía y capacidades debe involucrarse en su autoformación.

El llamado kantiano de Sapere aude: «iTen el valor de servirte de tu propia razón!: he aquí el lema de la ilustración» (Kant, 1994 [1784]) manifiesta que la educación, sobre todo la de los ciudadanos, depende de uno mismo. En gran parte, los fracasos estudiantiles se deben a la falta de una actitud más autónoma. Es fácil evadir la responsabilidad y culpar a la familia, al Estado o a los MCS; sin embargo, la verdadera responsabilidad, o al menos 
una responsabilidad compartida, recae también en el alumno. Cada uno cosecha lo que siembra, cada uno debe asumir su propia responsabilidad. A eso le denominamos «meritocracia».

Savater (1991) califica de imbécil al hombre que necesita de otros para avanzar o para justificarse por no hacerlo. Precisamente, la única obligación del hombre en esta vida es la de «no ser imbéciles» (p. 46). Hay varios tipos de imbéciles y todos necesitan apoyarse en cosas de fuera, ajenas, que no tienen nada que ver con su libertad o su reflexión. «Lo contrario de ser imbécil es tener conciencia, tener mejor oído ético y un buen gusto moral espontáneo» (p. 47), que con la práctica se afirma y se desarrolla hasta convertirse en virtud. Es mejor estar atentos a nuestras acciones. ¿Lo que se hace corresponde realmente con lo que queremos? Es importante desarrollar el criterio moral para evitar las actitudes negativas (mentir, robar, hacer daño, etc.). La formación ética es una invitación a elegir el bien y evitar el mal. Se trata de buscar lo mejor para uno mismo, pero para que esta búsqueda no se convierta en egoísmo, relacionado con la imbecilidad, también es necesario buscar el bien para los demás.

\section{Las políticas educativas del Estado}

El Estado debe establecer como políticas sectoriales el principio de la libertad y el de la obligatoriedad: el primero faculta a la familia a elegir la institución y el modelo educativo de su preferencia; el segundo precisa la responsabilidad de la familia con la educación de su prole. Considerando estos dos principios, el Estado debe asumir su deber de apoyar a la familia en pro del desarrollo social.

En una sociedad de oportunidades, los jóvenes pueden elegir la universidad (pública o privada) afín a sus intereses. Si la familia cuenta con los medios económicos suficientes, asumirá los costos de la educación de los hijos; de lo contrario, previa evaluación, la universidad o el Estado deben brindar el apoyo subsidiario. Parte del presupuesto destinado cada año a la educación debe usarse en subsidios. El esfuerzo y el mérito son las razones por las que no se puede otorgar beneficios iguales a todos. Las oportunidades y los derechos pueden ser iguales, pero sin estropear el 
mérito de cada uno. Por ello existen también los créditos educativos (para pensiones, vivienda y adquisición de herramientas tecnológicas); opción que debe estar dirigida a quienes trabajan y pueden devolverlos fraccionadamente. En vista de que no tienen un fin productivo material, estos créditos deben caracterizarse por tasas de interés cero (MINEDU, 2014).

De acuerdo a las normas constitucionales, el sistema y el régimen educativo peruano son descentralizados. El Estado, mediante sus diversos entes gubernamentales, coordina las políticas educativas, formula los lineamientos generales de los planes de estudios y establece los requisitos mínimos de la organización y gestión de los centros educativos. Además, supervisa el cumplimiento de la ley y promueve la calidad de la educación, al mismo tiempo de asegurar que nadie se vea impedido de recibirla por razones de su situación económica o por limitaciones mentales o físicas. Finalmente, prioriza la asignación de recursos adecuados del presupuesto de la nación (CPP, 1993, Art. 16).

\section{La inversión en educación}

La crisis educativa está motivada, en gran parte, por la poca inversión económica estatal. En el caso peruano, la inversión en educación es precaria. El año 2019 se asignó al sector solo un 3.82\% del presupuesto anual, y en el año 2020 fue de $4.25 \%$. Las perspectivas de inversión mejoran para el año 2022, con una asignación del 7.9\% (Diario Oficial El Peruano, 2021), cifra que aún resulta insuficiente para cubrir los gastos de los miles de niños y jóvenes peruanos que ya están en el sistema.

Invertir en la alimentación de los estudiantes no solo es una forma de prevenir la anemia, sino también una condición para el desarrollo de aprendizajes significativos (MINEDU, 2014). Es necesario que se implementen comedores en todas las escuelas, colegios y universidades. Asimismo, la inversión en tecnología para la educación es un reto que la escuela actual, la familia y el Estado deben asumir.

Invertir en la educación universitaria (pregrado y posgrado) es asegurar mayores activos para el Estado y para la sociedad. Las especializaciones, 
maestrías y doctorados son el punto de partida para el desarrollo científico, pero implican una gran inversión. Los escándalos provocados por autoridades de algunas universidades, debido a sueldos exorbitantes, malversación de fondos y corrupción, pueden evitarse con una regulación equilibrada que priorice el desarrollo de la universidad, de la ciencia y de la calidad de los procesos educativos.

Los beneficios de los posgrados, programas con mayor profundización científica, no son solo para los maestros, sino también para las instituciones educativas, los educandos y el Estado. Las primeras podrían contar con una plana docente más capacitada, mejorarían las competencias académicas del profesor y el Estado incrementaría sus contribuyentes de quinta categoría: en la actualidad hay maestros con estudios de posgrado que tributan en esta categoría, pero son pocos.

\section{Un diseño curricular para una educación integral}

El currículo educativo actual, basado ya no en objetivos sino en competencias, y los contenidos educativos reducidos a temas de carácter práctico y utilitario, donde la perspectiva de la integralidad no se considera, necesitan una verdadera revolución educativa, valorando tanto la ciencia y la tecnología como lo jurídico-político, lo ético-moral y los valores (ComteSponville, 2013, como se citó en Leuridan, 2021).

La educación es uno de los problemas de las políticas estatales, dependiendo del tipo de Estado o del sistema de gobierno imperante. Los modelos verticalistas y absolutistas (socialismo y neoliberalismo) son un peligro porque deshumanizan la educación reduciéndola a los intereses estatales o a los de las elites dominantes. El socialismo impulsa una educación materialista con énfasis en la búsqueda de resultados, mientras que el neoliberalismo postula una educación-empresa, donde lo que importa es el negocio y la formación de competencias inherentes a los intereses económicos del mercado globalizado. El hombre mediocre, incapaz de usar su imaginación para concebir ideales y un futuro por los cuales luchar, sumiso a la rutina y a los prejuicios, termina convirtiéndose en parte de un rebaño ciego, de una sociedad condenada al subdesarrollo (Ingenieros, 2000; Mailhe, 2013). 
Si el conductismo, el cognitivismo y el constructivismo intentaran hoy imponerse unilateralmente no prosperarían. Igualmente, vistos desde la exclusividad, ni la educación autoritaria, ni el autoaprendizaje tienen futuro (Ferry, 2010, como se citó en Leuridan, 2021). La idea de la unidad en la diversidad es la más adecuada para superar estas crisis, porque expresa el sentido de la integralidad humana. Hoy más que nunca es urgente una educación interactiva, que complemente la enseñanza con el aprendizaje, al estudiante con el docente, los diversos saberes humanos, ciencia y tecnología con lo jurídico-político, y ambas con el saber ético-moral y los valores, la materia con el espíritu, y la escuela con la familia y el Estado.

Peñaloza (2005) propone el desarrollo del currículo integral, cuyos principios fundamentales son la diversificación y los objetivos dirigidos a la formación compleja de la persona humana. La educación de los niños, adolescentes y jóvenes debe realizarse teniendo en cuenta la multidisciplinariedad del conocimiento.

El conductismo reduce al hombre al aprendizaje sociocultural, hecho que en ambientes verticalistas termina siendo un proceso de alienación. El estudiante no es un recipiente que debemos llenar, sino un sujeto lleno de potencialidades que es preciso despertar (Montaigne, como se citó en Savater, 1997). Con toda seguridad los conductismos terminan casi siempre en dogmatismos impositivos y en muchos casos absurdos, como se puede ver en los países fundamentalistas que olvidan la naturaleza cambiante, innovadora del ser humano e imponen criterios educativos que, muchas veces, significan la negación de sus derechos, como es el caso de las mujeres excluidas de la educación en Afganistán. El cognitivismo absoluto anula el rol del maestro y reduce al estudiante a la búsqueda de la autonomía total que casi siempre termina en el nihilismo y en el individualismo (Leuridan, 2021).

Las instituciones educativas deben superar los emprendimientos mercantiles. Las experiencias curriculares reflexivas (filosofía, ética, cívica, axiología) ayudarán al estudiante a adquirir gradualmente un sentido de responsabilidad frente a los retos de la cultura, del orden y de la propia vida. El desarrollo de la capacidad de diálogo y de escucha, así como de la solidaridad, hará del hombre un agente importante de la convivencia 
humana, tan necesaria en nuestras sociedades individualistas y divididas (Fuentes et al., 2012).

\section{La acreditación y la calidad educativa}

La acreditación es indispensable para asegurar la calidad de la oferta educativa. Sin embargo, no se ha logrado como se esperaba. Martínez et al. (2017) sostienen que, en América Latina, el sistema de acreditación tiene una serie de problemas: se centra en el área administrativa y no en el desempeño académico, incrementando el aparato burocrático; sus procesos tienden a ser una simulación; no hay una participación real de la comunidad educativa; y la credibilidad en los organismos acreditadores aún no se ha consolidado. A pesar de las deficiencias mencionadas, el presente estudio considera que el sistema de acreditación educativa es necesario, pero debe tener una vigencia temporal, de tal modo que, cumplido el tiempo indicado, las instituciones educativas puedan tomar decisiones adecuadas que les permitan el logro de mejores estándares de calidad. La acreditación debe diseñar estrategias que permitan la participación real de la comunidad educativa y promover el desarrollo de competencias, pero también de contenidos y valores.

\section{La innovación educativa}

La innovación educativa es una necesidad inherente a la naturaleza cambiante del hombre y de la sociedad. No se reduce a invertir en ciencia y tecnología, a una modificación del currículo o de las estrategias didácticas. Savater (1991) critica a la sociedad contemporánea porque ha permitido la globalización de la economía, del mercado, de la ciencia, pero no de la ética. Para ser de carácter integral, la verdadera innovación está en la renovación del hombre, que satisfaga sus necesidades, sobre todo la del fomento de los valores (Juan Pablo II, 1979). Es por ello que la innovación debe ser también el retorno a la reflexión y a la recuperación de los valores éticos y morales, inherentes a la búsqueda de la felicidad humana.

Las acciones de planificación, ejecución y evaluación educativa, en muchos casos copiadas de propuestas curriculares, enfoques y currículos diversos, no han logrado sus objetivos. En el Perú de las últimas décadas, la bandera de la educación moderna es el currículo por competencias. El 
MINEDU, desde esta perspectiva, propone una serie de acciones para el desarrollo de capacidades y habilidades, pero no muestra el mismo entusiasmo en lo referente al desarrollo ético y al aprendizaje de los valores.

Los logros académicos y conductuales (éticos) son la garantía del hombre feliz. El hombre feliz (o satisfecho) es capaz no solo de valorarse a sí mismo, sino también de valorar a los demás, es optimista en el trabajo, en sus proyectos y en la búsqueda de sentido para su vida (Leuridan, 2021).

La reforma del sistema educativo debe apuntar a políticas autogestionarias, contextualizadas e interculturales, que superen la imitación de modelos muchas veces fracasados. Es necesario centrarse en una educación que ayude a la solución de los problemas de nuestra sociedad, de cada región y de cada grupo sociocultural, que contribuya al logro de los objetivos y metas planificados.

\section{Conclusiones}

Una de las metas más importantes de la educación humana es el logro de la calidad, y esta depende de las políticas públicas y de un planeamiento curricular que considere a la educación como un proceso de formación íntegra de la persona. Una de las tareas de este proceso es superar las concepciones reduccionistas del materialismo, del cientificismo o de la tecnología, y trascender a una visión holística de la persona humana, que permita su realización plena.

El reconocimiento del derecho universal e inalienable a la educación es una prioridad. Esta nueva perspectiva significa la superación de los prejuicios, de los falsos privilegios y de sus diversas consecuencias.

La finalidad del proceso educativo centrado en la persona como un fin y no como un medio, y en su desarrollo integral, también tiene preeminencia, pues «el nuevo orden que buscamos está constituido sobre el hombre» (Kant, como se citó en Leuridan, 2021, p. 100).

La educación es tarea de todos. La familia, la escuela, el Estado, los medios de comunicación social, la sociedad en general y el mismo estudiante hacen fuerza común por la formación integral de las nuevas generaciones. 
Los docentes deben desarrollar, junto a las diversas capacidades inherentes a su labor, la vocación de servicio, la formación ética y axiológica que los determine como ejemplos y como verdaderos maestros.

Las políticas educativas del Estado deben ser claras en lo que se refiere a los fines de la educación, a la inversión, a la innovación curricular y tecnológica, acordes con la promoción de su calidad. La innovación debe ir más allá de los cambios y mejoras en infraestructura y tecnología, centrándose en la del docente, considerando que este es el gran aliado en la toma de decisiones en los diversos contextos de las actividades educativas.

El sistema educativo universitario necesita fortalecerse no solo en lo que concierne la calidad, sino también en la descentralización y modernización. La educación convertida en negocio, generada por la corriente neoliberal, debe superar las perspectivas de la robotización y preparar al hombre para convertirse en agente de su propio destino y del de su sociedad.

Las políticas subsidiarias son hoy más necesarias que nunca. Gracias a estas políticas, los jóvenes con talento, pero débiles económicamente, pueden acceder a diversas oportunidades educativas. Las políticas inclusivas permiten que más jóvenes tengan acceso al derecho humano de educarse.

\section{Referencias}

Alarcón, H. H., Flores, K. N. y Alarcón, M. A. (2018). Perú: políticas que aseguran la calidad de la educación superior. InterMeio: revista do Programa de Pós-Graduação em Educação, 24(47), 17-35. https://1library.co/ document/z1g7v7ez-peru-politicas-aseguran-calidad-educacion-superior.html

Bauman, Z. (2004). Modernidad líquida. Cuarta edición. FCE. https://catedraepistemologia.files.wordpress.com/ 2009/05/modernidad-liquida.pdf

Benedicto XVI. (2009). Caritas in veritate. Libreria Editrice Vaticana. https://www.vatican.va/content/benedict-xvi/ es/encyclicals/documents/hf_ben-xvi_enc_20090629_caritas-in-veritate.html

Cabra, F. y Marciales, G. P. (2009). Nativos digitales: ¿ocultamiento de los factores del fracaso escolar? Revista Iberoamericana de Educación, 50, 113-130. https://rieoei.org/historico/documentos/rie50a06.pdf

Comisión de Derechos Humanos de la ONU. (1948). Declaración Universal de los Derechos Humanos. https:/l uww.un.org/es/about-us/universal-declaration-of-human-rights

Constitución Política del Perú [CPP]. (1993). Décima tercera edición oficial. Con las reformas ratificadas en el Referéndum de 2018. https://www.minjus.gob.pe/wp-content/uploads/2019/05/Constitucion-Politica-del-Perumarzo-2019_WEB.pdf 
Delors, J. (1994). La educación encierra un tesoro. Unesco. https://www.uv.mx/dgdaie/files/2012/11/CPP-DCDelors-Los-cuatro-pilares.pdf

Diario Oficial El Peruano. (2021, 31 de agosto). Presupuesto 2022 para Educación crece 7.9\% y es mayor al de los últimos tres años. Se considera una asignación de 35,758 millones de soles. https://elperuano.pe/noticia/ 128068-presupuesto-2022-para-educacion-crece-79-y-es-mayor-al-de-los-ultimos-tres-anos

Dussel, E. (2011). Carta a los indignados. Los Nuestros-La Jornada ediciones. https://enriquedussel.com/txt/ Textos_Libros/63.Carta_a_los_indignados.pdf

Fuentes, R., Gamboa, J., Morales, K., Retamal, N. y San Martín, V. (2012). Jean Piaget, aportes a la educación del desarrollo del juicio moral para el siglo XXI. Revista Convergencia Educativa, 1, 55-69. http://revistace.ucm.cl/ article/view/262/246

Hildebrandt, C. (2021). Confesiones de un inquisidor. Memorias de César Hildebrandt en diálogo con Rebeca Diz Rey. Debate.

Ingenieros, J. (2000). El hombre mediocre. Elaleph.com. http://upcndigital.org/ ciper/biblioteca/Lecturas\%20tempranas/ Jose $\% 20$ Ingenieros $\% 20-\% 20$ El\%20hombre\%20mediocre.pdf.

Juan Pablo II. (1979). Discurso del santo padre Juan Pablo Il a más de seis mil estudiantes universitarios procedentes de todo el mundo. Libreria Editrice Vaticana. https://www.vatican.va/contentjohn-paul-ii/es/speeches/1979/april/ documents/hf_jp-ii_spe_19790410_studenti.html

Kant, E. (1994 [1784]). Respuesta a la pregunta ¿Qué es la llustración? Traducción de R. Jaramillo (1986). Revista Colombiana de Psicología, 3, 7-10. https://dialnet.unirioja.es/servlet/articulo?codigo=4895205

Leuridan, J. (2021). El sentido de las dimensiones éticas de la vida. Generis Publishing.

Mailhe, A. (2013). El laberinto de la soledad del genio o las paradojas del hombre mediocre. Varia Historia, 29(49), 197-216. https://www.scielo.br/j/vh/a/QPDVbwpWtVcGV7bwyFr6DgP/?format=pdf\&lang=es

Martínez, J. E., Tobón, S. y Romero, A. (2017). Problemáticas relacionadas con la acreditación de la calidad de la educación superior en América Latina. Innovación Educativa 17(73), ene./abr. http://www.scielo.org.mx/ scielo.php?pid=S1665-26732017000100079\&script=sci_arttext

Ministerio de Educación [MINEDU]. (2014). Lineamientos de política para un sistema de becas y créditos subsidiados por una educación superior de calidad. Pronabec. http://www.minedu.gob.pe/minedu/archivos/ Lineamientos_IMP.pdf

Montenegro, W. (2016). Saber estudiar con las técnicas y estrategias del método holístico y la PNL. Saber estudiar es la clave para poder obtener resultados exitosos. Cultura, 30, 173-224. https://www.revistacultura.com.pe/ revistas/RCU_30_saber-estudiar-con-las-tecnicas-y-estrategias-del-metodo-holistico-y-la-pnl.pdf

Montenegro, W. (2018). Pedagogía del amor y PNL para la educación integral. El desarrollo humano integral de la persona. Cultura, 32, 279-322. https://www.revistacultura.com.pe/revistas/RCU_32_pedagogia-del-amor-y-pnlpara-la-educacion-integral-el-desarrollo-humano-integral-de-la-persona.pdf

Montenegro, W. (2020). El amor en tiempos de pandemia. Cultura, 34, 199-232. https://www.revistacultura.com.pe/ revistas/RCU_34_amor-pandemia.pdf

Paulo VI. (1965a). Gravissimum educationis [GE]. Declaración del Concilio Vaticano Il sobre la educación cristiana. Editorial Vaticana. https://www.vatican.va/archive/hist_councils/ii_vatican_council/documents/vatii_decl_19651028_gravissimum-educationis_sp.html

Paulo VI. (1965b). Gaudium et Spes. Constitución Pastoral sobre la Iglesia en el mundo actual. Editorial Vaticana. https://www.vatican.va/archive/hist_councils/ii_vatican_council/documents/vat-ii_const_19651207_gaudium-etspes_sp.html 
Peñaloza, W. (2005). El Currículo Integral. Tercera edición. Universidad Nacional Mayor de San Marcos. https:/l curriculoyevaluacion. files.wordpress.com/2012/08/curriculo.pdf

Salazar, E. (2020, 28 de octubre). Calidad educativa: la promesa detrás de las millonarias exoneraciones tributarias. OjoPúblico https://ojo-publico.com/2198/educacion-la-promesa-detras-de-las-exoneracionesfiscales\#: :text=En\%20el\%20Per\%C3\%BA\%20la,por\%20equipos\%20y\%20bienes\%20importados

Savater, F. (1991). Ética para Amador. https://www.escatep.ipn.mx/assets/files/escatep/docs/Docencia/Lectura/EticaPara-Amador.pdf

Savater, F. (1997). El valor de educar. Ariel. https://www.ivanillich.org.mx/Conversar-educar.pdf

Trahtemberg, L. (2016). La educación del siglo XXI. Entrevista. https://www.trahtemberg.com/entrevistas/2807-audioy-texto-leon-trahtemberg-y-la-educacion-del-siglo-xxi.pdf

Turienzo, R. (2016). El pequeño libro de la motivación. Alienta. https://uwww.planetadelibros.com/libros_contenido_extra/ 34/33578_EL_PEQUENO_LIBRO_DE_LA_MOTIVACION.pdf 